\title{
sciendo
}

\author{
RESEARCH PAPERS FACULTY OF MATERIALS \\ SCIENCE AND TECHNOLOGY IN TRNAVA \\ SLOVAK UNIVERSITY OF TECHNOLOGY \\ IN BRATISLAVA
}

2019, Volume 27, Number 44

DOI 10.2478/rput-2019-0007

\section{STUDY OF EXPLOSION CHARACTERISTICS OF THE WHEAT FLOUR DUST CLOUDS IN DEPENDENCE OF THE PARTICLE SIZE DISTRIBUTION}

\author{
Richard KURACINA ${ }^{1}$, Zuzana SZABOVÁ ${ }^{1}$, Eva BURANSKÁ ${ }^{1}$ \\ ${ }^{1}$ SLOVAK UNIVERSITY OF TECHNOLOGY IN BRATISLAVA, \\ FACULTY OF MATERIALS SCIENCE AND TECHNOLOGY IN TRNAVA, \\ INSTITUTE OF INTEGRAL SAFETY \\ UliCA JÁnA BotTu 2781/25, 91724 TRNAVA, SlovaKia \\ e-mail: richard.kuracina@stuba.sk, zuzana.szabova@stuba.sk,eva.buranska@stuba.sk \\ Received: 30.04.2019, Accepted: 05.06.2019, Published: 25.07.2019
}

\begin{abstract}
Fire protection is an important part of the industry where flammable and explosive dusts are found. Production, storage and transport of food powders such as flour can be very dangerous in terms of explosiveness. The article deals with the measurement of explosion characteristics of wheat flour dust. The measurements were carried out according to EN 140341+A1:2011 Determination of explosion characteristics of dust clouds. Part 1: Determination of the maximum explosion pressure $p_{\max }$ of dust clouds and the maximum rate of explosion pressure rise according to EN 14034-2+A1:2012 Determination of explosion characteristics of dust clouds - Part 2: Determination of the maximum rate of explosion pressure rise $(\mathrm{dp} / \mathrm{dt})_{\max }$ of dust clouds. A sample of wheat flour with a median particle size 84 um exhibits the maximum explosion pressure 7.00 bar at the concentration of $600{\mathrm{~g} . \mathrm{m}^{-3}}^{-3}$ and then explosion constant is

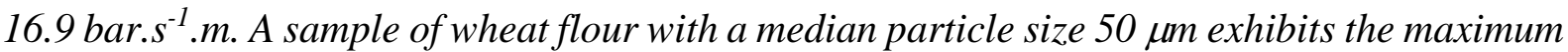
explosion pressure 7.97 bar at the concentration of 1000 g. $\mathrm{m}^{-3}$ and the explosion constant 54.9 bar.s ${ }^{-1} . m$. Based on the results of the measurements, we found that the particle size distribution has a significant influence on the explosion parameters of the wheat flour samples.
\end{abstract}

\section{Key words}

Wheat flour dust clouds, explosion characteristic, maximum explosion pressure, maximum rate of explosion pressure rise

\section{INTRODUCTION}

A dust explosion needs to be triggered by an ignition source of sufficient energy and simultaneously requires the presence of dust clouds of appropriate concentration and an atmosphere containing enough oxygen to permit combustion. The combustion process leads to a rapid and significant increase in pressure, typically up to $700-1000 \mathrm{kPa}$ within a confined 
space; such pressures could lead to the fracture and collapse of a silo or to a burst of the silo roof and upper walls with resultant flying projectiles [1].

The highest risk of explosion poses primary threat in the production processes, where dust is handled in some way. Such processes are used, for example, in the food, pharmaceutical or chemical industries. Technologies that companies use for milling, drying, pneumatic or mechanical transport, storage and filtration are highly susceptible to self-ignition, occurrence of fire and explosion. A series of accidents, fires and explosions, which happened in the past, turned attention of experts to the development of the systems and devices that could protect industrial technologies from these events [2].

A dust explosion could be triggered when flammable particulates suspended in the air encounter ignition sources with sufficient energy. Combustible dust can be found in the form of a by-product in various industries such as drilled-charcoal powder in coal mining and wood powder in the wood industry, or in the form of raw materials or intermediate products such as sugar powder in the food processing plants. Aside from high temperatures and overpressures caused by dust explosions, toxic gases can also be produced in the violent chemical reactions. Thus, dust explosions pose significant threats to people, assets, and the environment. Dust explosions have caused numerous losses in industry [3].

According to the previous research of Eckhoff [4], fuel, oxidant, ignition source, confinement, and suspension are the essential factors for a dust explosion [2].

Properties of dust clouds and settled dust are characterized by the Lower Explosive Limit (LEL), the maximum explosion characteristics (maximum explosion pressure $p_{\text {max }}$, maximum rate of explosion pressure rise $\left.(d p / d t)_{\max }\right)$, minimum ignition energy $E_{\min }$, minimum ignition temperature of dust clouds $t_{r o z}$, induction period for ignition $\tau_{i}$ and Limiting oxygen concentration (LOC) [5].

The article presents the practical measurement of the maximum explosion pressure and the maximum rate of explosion pressure rise of the wheat flour dust clouds in dependence of the particle size distribution. Research on the dependence of the explosion parameters on the granulometry of the samples has also been dealt in [6,7 and 8].

The measurements were carried out in accordance with EN 14034-1+A1:2011 Determination of explosion characteristics of dust clouds. Part 1: Determination of the maximum explosion pressure $p_{\max }$ of dust clouds and the maximum rate of explosion pressure rise according to EN 14034-2+A1:2012 Determination of explosion characteristics of dust clouds - Part 2: Determination of the maximum rate of explosion pressure rise $(d p / d t)_{\max }$ of dust clouds [9].

\section{MATERIALS AND METHODOLOGY OF EXPERIMENT}

For the measurement of monitored characteristics, we used a modified chamber of KV 150M2. Scheme of the chamber is shown in Figure 2. Dust clouds in this unit is carried out mechanically. From the tank with volume 5.5 liters, the compressed air is transmitted by a fast opening electromagnetic valve to inner space of the chamber which a volume of 291 liters. The sample is located on a plate and spread by the compressed air at the pressure of $9.5 \mathrm{bar}$. The compressed air is directed to the sample through the metal profiled sheeting. The sample is ignited by a nitrocellulose igniter after spreading the sample. The igniter works on a resistive principle. Immediate ignition of nitrocellulose is achieved by the power source with parameters of $60 \mathrm{~V} \mathrm{DC}$ and 5.5 A, which is supplied to the resistance wire and results in an immediate burn and interruption of the wire. Ignition energy of the nitrocellulose used in initiator is $10 \mathrm{~kJ}$. 


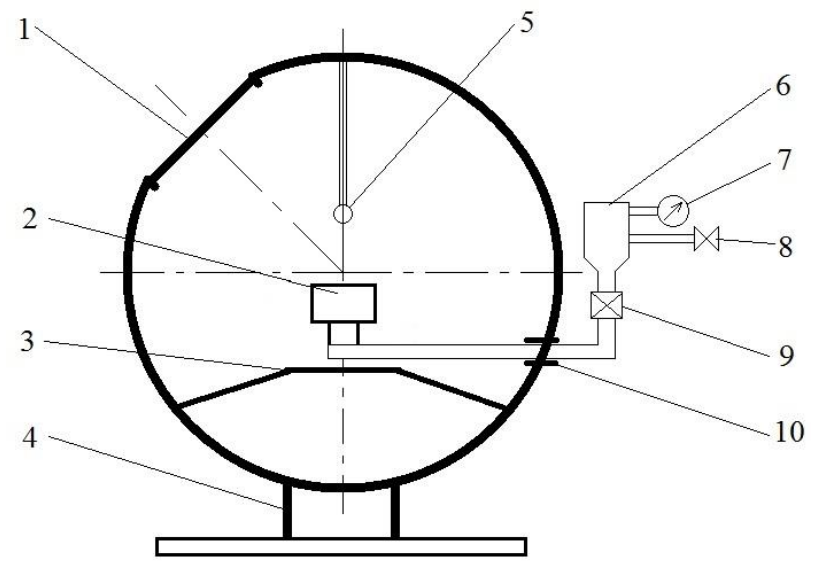

Fig. 1 Scheme of a modified KV 150-M2 chamber (1-lid, 2- disperser, 3-desk, 4- base, 5nitrocellulose igniter, 6-vessel, 7- manometer, 8-compressed air inlet valve, 9-fast opening electromagnetic valve, 10- window

Ignition of dust and dispersion of the dust is timed by a solid state timing relay. The relay has a fixed time interval set between the opening of the fast opening valve and with the connecting power to the initiator clamps. Time delay was set on $260 \mathrm{~ms}$. The pressure changes inside the chamber were recorded by the pressure transducer with $\mathrm{mA}$ output and the maximum measurable overpressure value of 20 bar. The pressure transducer is powered by a stabilized 24 $\mathrm{V}$ DC source. Response time of pressure transducer is $0.5 \mathrm{~ms}$ and the current value is recorded through the datalogger. The measured samples were two different wheat flour dusts. Particle size of samples is shown in Table 1.

\begin{tabular}{||l|l|l||}
\hline \multicolumn{2}{||l|}{ Table 1 Particle size of wheat flour dust samples } \\
\hline \hline Particle size & Sample 1\% $\%_{\text {wg. }}$ & Sample 2 \% wg. \\
\hline \hline$>500 \mu \mathrm{m}$ & 0.00 & 0.25 \\
\hline $250-500 \mu \mathrm{m}$ & 0.13 & 0.56 \\
\hline $200-250 \mu \mathrm{m}$ & 5.76 & 5.83 \\
\hline $150-200 \mu \mathrm{m}$ & 33.94 & 19.48 \\
\hline $90-150 \mu \mathrm{m}$ & 24.18 & 17.04 \\
\hline $56-90 \mu \mathrm{m}$ & 22.53 & 17.75 \\
\hline $0-56 \mu \mathrm{m}$ & 9.05 & 39.09 \\
\hline \hline median value: & $84 \mu \mathrm{m}$ & $50 \mu \mathrm{m}$ \\
\hline \hline moisture & $15.0 \%$ & $7.2 \%$ \\
\hline
\end{tabular}

Measurement of the parameters was carried out on the apparatus described above. The igniter was nitrocellulose of a weight from $1.25 \mathrm{~g}$. As mentioned above, the weight of the nitrocellulose corresponded to the energy of the initiator with the value of $2 \times 5 \mathrm{~kJ}$.

The current in the circuit was measured by the $269.3 \Omega$ resistor with a data logger. The values were recorded at the rate of 2000 values/second. Recording of the pressure changes during the explosion of dust clouds was measured in the concentrations range $150-1000 \mathrm{~g} / \mathrm{m}^{3}$. 


\section{RESULTS AND DISCUSSION ON RESULTS}

The values of pressure depending on the time obtained by the measurement are shown in Figures 3 and 5. The results suggest that the increasing concentration of the dust leads to the increase of the pressure value and the pressure rise value in the chamber. Tab. 2 shows the explosion characteristics of the wheat flour dust clouds samples at various concentrations.

By comparing the measurement results with the Gestis-Dust-Ex database [10], we determined that the measurement results of both samples correspond to the measurements in the database. The Gestis database for Sample 1 lists the maximum explosion pressure of 7.2 bar and the explosion constant of $\mathrm{K}_{\mathrm{st}}$ of $41 \mathrm{bar}^{\mathrm{s}} \mathrm{s}^{-1} \mathrm{~m}$. For Sample 2, the Gestis database lists the maximum pressure of 7.3 bar and the explosion constant of 59 bar. $\mathrm{s}^{-1} . \mathrm{m}$.

\begin{tabular}{|l|l|l|l|l|}
\hline \multicolumn{2}{|l|}{ Table 2 Explosion characteristics of the wheat flour dust samples } \\
\hline \multirow{2}{*}{$\begin{array}{l}\text { Concentration } \\
\left(\mathrm{g} / \mathrm{m}^{3}\right)\end{array}$} & \multicolumn{2}{|c|}{ Sample 1 } & \multicolumn{2}{c|}{ Sample 2 } \\
\cline { 2 - 5 } & Pmax (bar) & $\mathrm{dP} / \mathrm{dt}\left(\right.$ bar. $\left.^{-1}\right)$ & Pmax (bar) & $\mathrm{dP} / \mathrm{dt}\left(\mathrm{bar} . \mathrm{s}^{-1}\right)$ \\
\hline 150 & 2.58 & 6.79 & 2.32 & - \\
\hline 250 & 3.54 & 11.54 & 4.87 & 24.23 \\
\hline 500 & 5.71 & 18.90 & 7.28 & 68.47 \\
\hline 600 & 7.00 & 25.49 & 7.31 & 82.81 \\
\hline 750 & 6.25 & 23.35 & 7.59 & 73.84 \\
\hline 1000 & - & - & 7.97 & 82.21 \\
\hline
\end{tabular}

$$
\begin{aligned}
& K_{s t, s 1}=\mathrm{d} P / \mathrm{d} t_{\text {max }} \times \sqrt[3]{V}=25.49 \times \sqrt[3]{0,291}=16.9 \text { bar. } \mathrm{s}^{-1} \cdot \mathrm{m} \\
& K_{s t, s 2}=\mathrm{d} P / \mathrm{d} t_{\text {max }} \times \sqrt[3]{V}=82.81 \times \sqrt[3]{0,291}=54.9 \text { bar. } \mathrm{s}^{-1} \cdot \mathrm{m}
\end{aligned}
$$

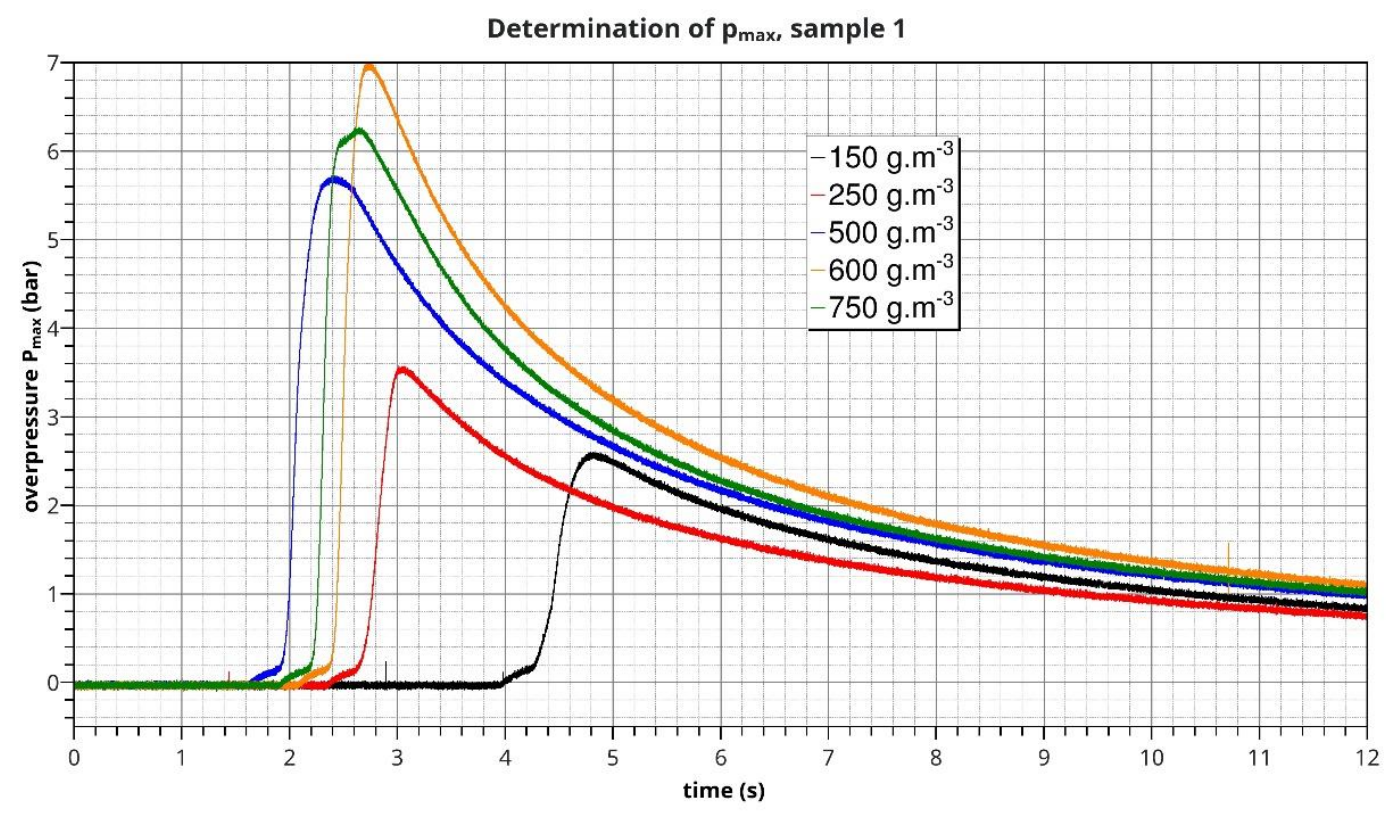

Fig. 2 Explosion pressure of sample 1 with various concentrations 


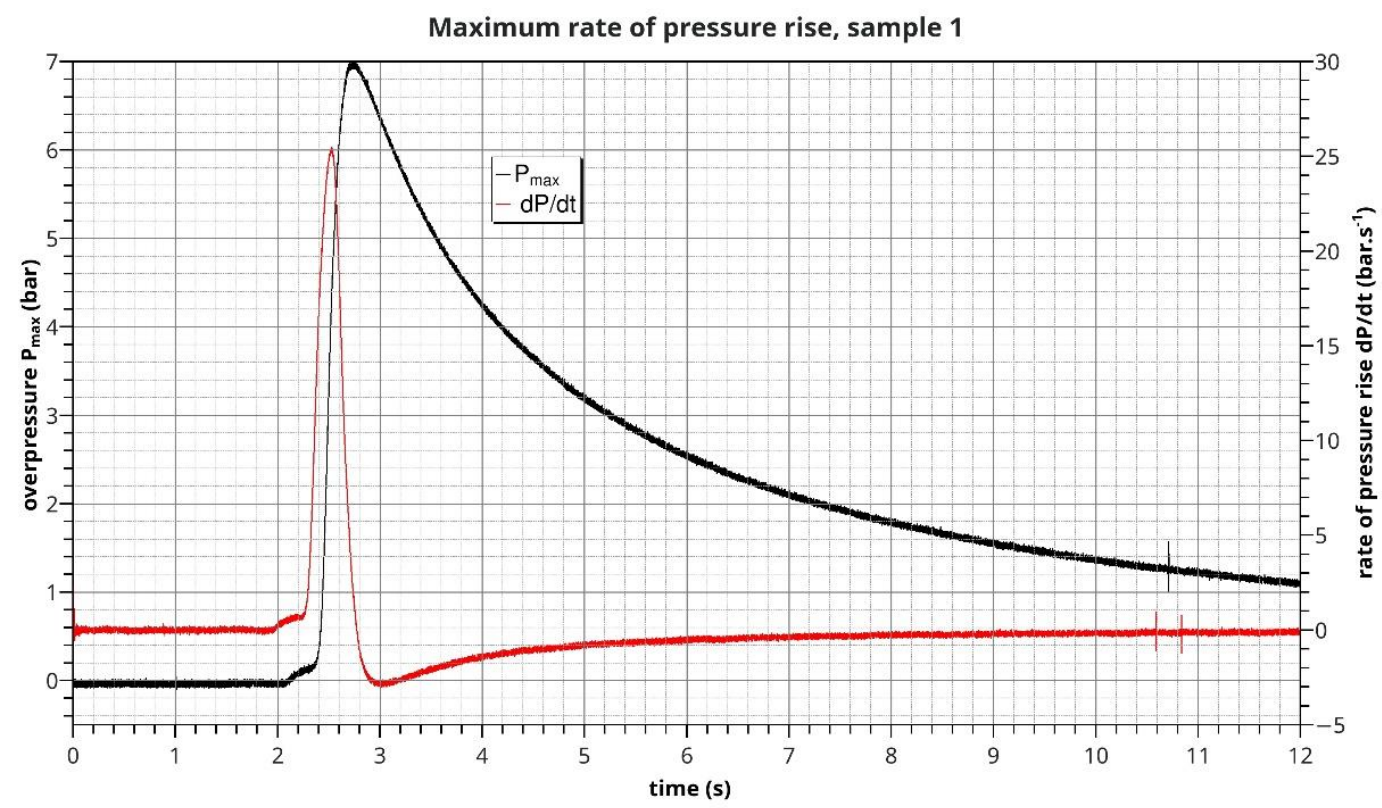

Fig. 3 Explosion pressure $P$ and pressure rise $d P / d t$ of sample 1 with the concentration of $600 \mathrm{~g} / \mathrm{m}^{3}$

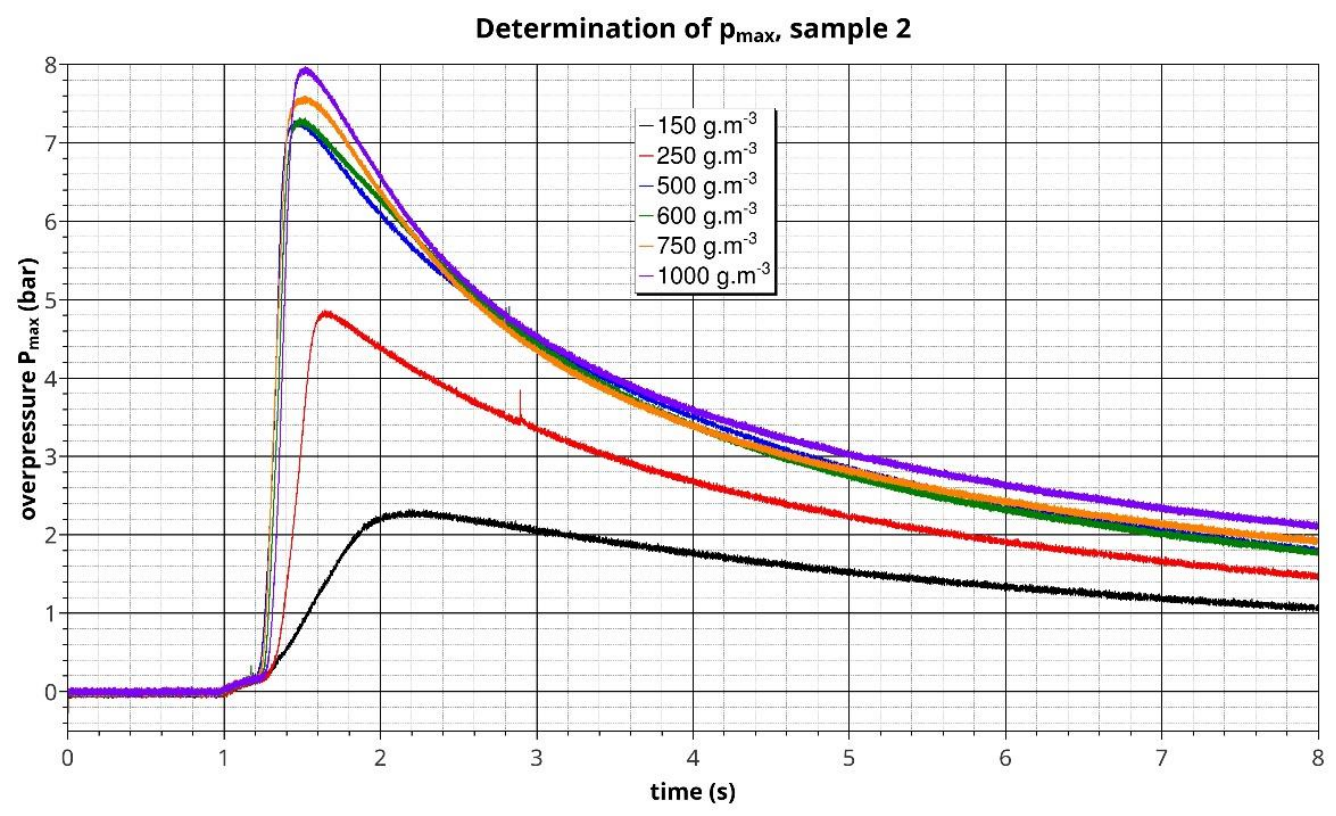

Fig. 4 Explosion pressure of sample 2 with various concentrations 


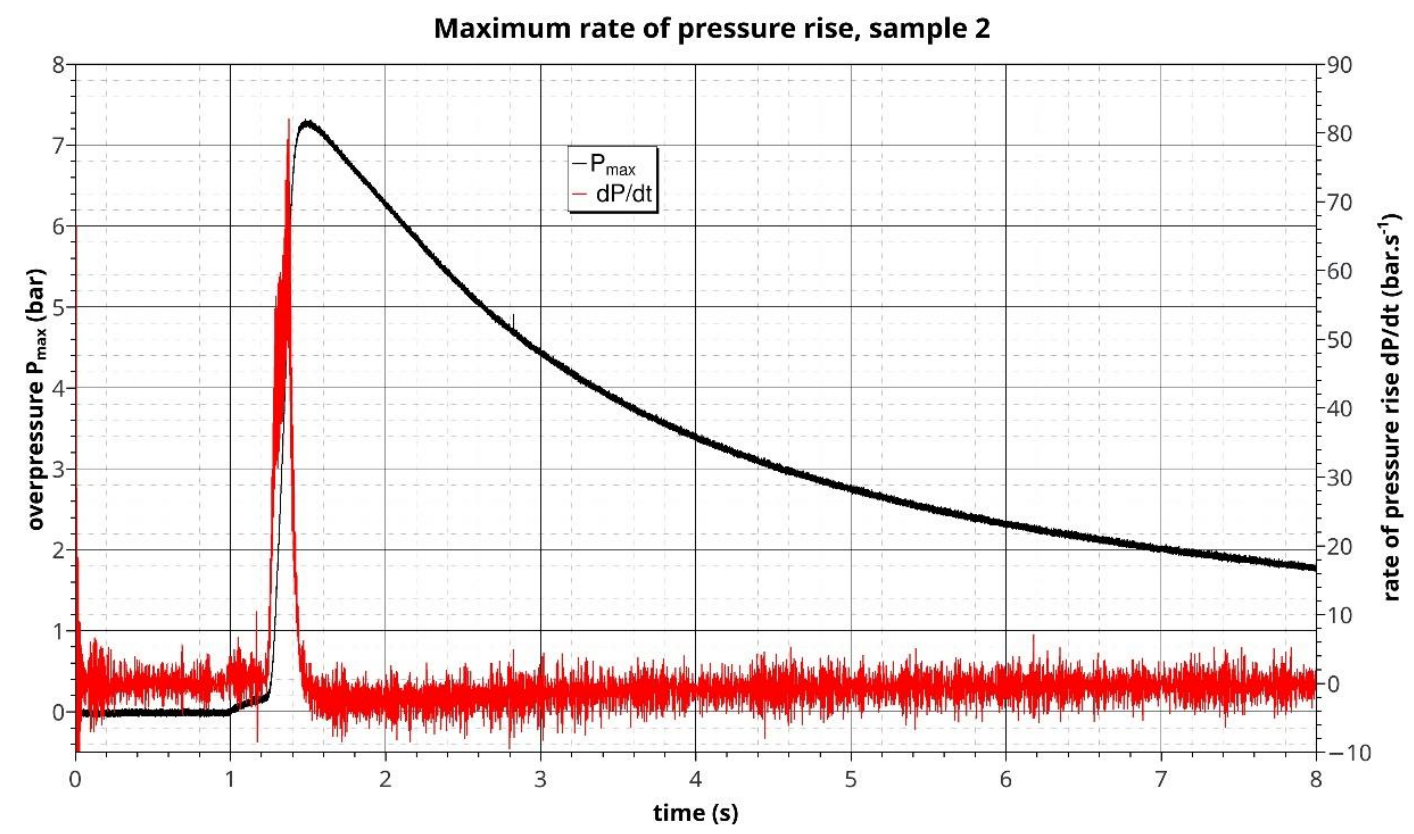

Fig. 5 Explosion pressure $P$ and pressure rise $d P / d t$ of sample 2 with the concentration of $600 \mathrm{~g} / \mathrm{m}^{3}$

\section{CONCLUSIONS}

The tests of the explosion of the wheat flour dust clouds by the device which parameters were described above proved that the maximum value of the pressure of Sample 1 (median value of particle size $84 \mu \mathrm{m}$ ) was reached at concentration of $600 \mathrm{~g} / \mathrm{m}^{3}$ and its value is 7.00 bar.

The maximum value of the pressure of Sample 2 (median value of particle size $50 \mu \mathrm{m}$ ) was reached at the concentration of $1000 \mathrm{~g} / \mathrm{m}^{3}$ and its value is 7.97 bar. The explosion constant $\mathrm{K}_{\mathrm{st}}$ of Sample 1 was calculated for the concentration of $600 \mathrm{~g} / \mathrm{m}^{3}$ and its value is $16.9 \mathrm{bar} . \mathrm{s}^{-1} . \mathrm{m}$. The explosion constant $K_{\mathrm{st}}$ of Sample 2 was calculated for the concentration of $600 \mathrm{~g} / \mathrm{m}^{3}$ and its value is 54.9 bar. $\mathrm{s}^{-1} . \mathrm{m}$.

On the basis of measurement, we found that the distribution of the particles has a significant impact on the parameters of the wheat flour dust samples. It can be concluded that the sample with smaller particles exhibits higher explosion parameters.

\section{Acknowledgements}

This research output was supported by the Slovak Research and Development Agency under the contract No. APVV-16-0223 and by the VEGA Project 1/1010/16.

\section{References}

[1] TASCÓN, A. 2017. Design of silos for dust explosions: Determination of vent area sizes and explosion pressures. Engineering Structures. 134, 1 - 10, ISSN 0141-0296

[2] S̆TROCH, P. 2016. Do not underestimate danger of explosion; Even dust can destroy equipment and kill. Perspectives in Science. 7, 312-316, ISSN 2213-0209

[3] YUAN, Z., KHAKZAD, N., KHAN, F., AMYOTTE, P. 2015 Dust explosions: A threat to the process industries. Process Safety and Environmental Protection, 98, 57 - 71, ISSN 0957-5820

[4] ECKHOFF, R.,K. 2003. Dust Explosions in the Process Industries, 3rd ed. Gulf Professional Publishing. 719 p. ISBN 9780750676021 
[5] DAMEC, J., 1993, Risk of industrial dust explosions (Part 4). In 150 Fire, No. 6, ISSN $0682-$ 8467

[6] CASTELlANOS, D., CARRETO-VAZQUEZ, V.A., MASHGUA, C.V., TROTTIER, R., MEIJA A. F., MANNAN, M.S. 2014. The effect of particle size polydispersity on the explosibility characteristics of aluminum dust. Powder technology. 254, 331 - 337, ISSN 0032-5910

[7] HONGMING, Z., XIANFENG, C., YING, Z., YI, N., BIHE, Y., HUAMING, D., SONG, H. 2017. Effects of particle size on flame structures through corn starch dust explosions. Journal of Loss Prevention in the Process Industries. 50(part A), 7 - 14, ISSN 0950-4230

[8] NOOR, A. A. K., RISZA, R., AZIZUL, B., NUR, S. A. R. 2016. Investigation of the Explosion Behaviour Affected by the Change of Particle Size. Procedia Engineering, 148, 1156 - 1161, ISSN 1877-7058

[9] STN EN 14034-3+A1:2012 Determination of explosion characteristics of dust clouds. Part 3:Determination of the lower explosion limit LEL of dust clouds

[10] GESTIS-DUST-EX, Database Combustion and explosion characteristics of dusts, IFA, online [2019-6-21]: http://staubex.ifa.dguv.de/exploergebnis.aspx?lang=e

\section{ORCID}

Richard Kuracina

0000-0003-1468-0820

Zuzana Szabová

$0000-0002-7886-1623$

Eva Buranská

0000-0002-2382-7508 